\title{
Palavra, ato, feitiço: algumas conjurações no campo da magia
}

\author{
Word, act, sorcery: a few conjurations made by magic groundings
}

\section{Léo Karam Tietboehl*}

Resumo: Este artigo parte de uma proposta terapêutica psicanalítica de talking cure e das premissas dos estudos a respeito de um performativo para conjurar referenciais e tecer considerações acerca do feitiço, tomando-o na sua dimensão de acontecimento singular e de natureza imprevisível. A discussão ocorrerá debruçada sobre os meios de um capitalismo e pautada a partir das ambivalên cias de uma ideia de fetiche. No seu elaborar, são retomadas algumas colocações sobre os interstícios entre magia e política para indicar a importância de uma dimensão incapturável no fazer científico.

Palavras-chave: Palavra; Ato; Feitiço; Magia; Elocuções Performativas; Ficção

Abstract: The present article departs from a psychoanalytical therapeutic proposal of talking cure, and also from the standings and studies around a performative, to conjure references and formulate considerations on the concept of spellworking - which is here taken as a singular and unpredictable happening. The discussion will operate By the ways of such debate, some statements that work around the interstices between magic and politics are taken up to indicate the importance of an uncatchable dimension for a scientific practice.

Keywords: Word; Act; Sorcery; Magic; Performative Speech; Fiction

\section{Apresentação}

Ao longo da elaboração deste texto, se procuram as conexões entre estas que podemos objetivamente definir como três vias argumentativas principais. Por um lado, se retomam as premissas de um pensamento e de uma prática psicanalíticos que entendem as elaborações discursivas como algo que se produz nas imediações de uma ficção. Por outro, importará introduzir uma lógica do performativo para que se possa entender o processo de constituição subjetiva e de uma realidade como muito permeado pelos jogos discursivos que se produzem desde regimes de identificação.

As duas vias se encontram atravessadas por uma talvez mais profunda, tecida nos interstícios entre os campos de uma verdade e de uma ficção, acerca das potencialidades de um saber que se constitui em relação com uma magia. Nesta senda, o feitiço será um elemento importante de análise por carregar consigo uma dimensão imprevisível de acontecimento - perceptível desde a dimensão de um dizer e também, de maneira tal-qual, de um fazer.

\section{Recordar, repetir, elaborar}

O título desta seção traz os indícios de uma formulação que, desde sua gênese, coloca os três elementos como fundamentais para uma prática psicanalítica. No texto que recebe o

I Psicanalista, psicólogo, mestre pelo Programa de Pós-Graduação em Psicanálise: Clínica e Cultura, Universidade Federal do Rio Grande do Sul, Porto Alegre, RS. E-mail: leokt2@gmail.com ORCID: https://orcid.org/oooo-0003-2416-6649 
mesmo nome desta seção, Sigmund Freud ${ }^{1}$ entrelaça as três dimensões de um recordar, de um repetir e de um elaborar para sustentar um método de cura pela fala baseado na lógica de associação livre ${ }^{2}$. As construções narrativas que se produzem desde a proposta terapêutica apostam em uma formulação de sentido que não se ocasiona antes, mas sódepois de um acontecimento de elaboração, pelo qual se podem perceber repetições que, em uma lógica de escuta do sintoma, mostram as marcas de uma ou outra discursividade singular.

O termo em itálico serve para assinalar um conceito que habita de maneira não tão aparente as colocações de Freud, sob o nome de Nachtraglichkeit, e que é retomado de maneira mais formalizada por Jacques Lacan 3 , conforme Jean Laplanche ${ }^{4}$ também aponta, sob o nome de après-coup - ou, em português, só-depois.

Para as elaborações deste artigo, importa o próprio fazer de uma ficção, que por um processo imaginativo inventa uma conjugação daqueles tempos que entenderíamos como separados - de um passado, presente ou futuro. Reinhardt Koselleck 5 é um historiador que apontará para a impossibilidade dessa separação, elaborando sobre os termos de uma temporalidade que não se podem referir senão de maneira conjugada. Pelas propostas de pensar que um futuro, um passado ou um presente se produzem sempre desde passados, presentes ou futuros outros, a serem inevitavelmente localizados em relação ao agora de uma análise, Koselleck faz ver que os processos só ocorrem a partir de um regime de associação - entre antes, depois e agora. Diferentemente de uma simples ideia de passado, presente ou futuro, o que compete a uma narrativa que se entende atravessada pela ficção é entender estes como tempos produzidos por uma associação de certo tempo a um outro tempo, que podemos pensar como um de enunciação, sempre diferido daquele que refere.

Émile Benveniste é quem teoriza sobre o momento de enunciação, necessário a qualquer dizer, e que engendra certo jogo de mão dupla a partir da presença de um locutor:

a presença do locutor em sua enunciação faz com que cada instância de discurso constitua um centro de referência interno. Esta situação vai se manifestar por um jogo de formas específicas cuja função é de colocar o locutor em relação constante e necessária com sua enunciação ${ }^{6}$.

A colocação abre espaço para uma discussão não apenas a respeito de uma tomada de posição no momento de enunciação, mas também para que pensemos o funcionamento de uma leitura.

Neste ensejo, importantes colocações podem se fazer em associação com a premissa psicanalítica de après-coup, no sentido de entender que a realidade é, sempre, vinculada a

\footnotetext{
${ }^{1} \mathrm{Na}$ leitura do psicanalista, “o paciente não recorda coisa alguma do que esqueceu ou reprimiu, mas expressa-o pela atuação ou atua-o. Ele o reproduz não como lembrança, mas como ação; repete-o, sem, naturalmente saber o que está repetindo" (FREUD, Recordar, repetir, elaborar, 196). O processo de análise cumpriria a função, nesta relação, de permitir uma enunciação desta repetição, junto a um reconhecimento da mesma.

${ }^{2}$ A regra fundamental da associação livre é de suma importância para um método psicanalítico. Freud a estabelece pela primeira vez em A Dinâmica da Transferência, mas esta se apresenta como uma prática desde o momento em que é afirmada a aposta em um método diferente do de hipnose. Em um texto chamado $O$ Método Psicanalítico de Freud, escrito pelo mesmo na terceira pessoa, o autor relaciona a importância de uma técnica terapêutica que ofereça as possibilidades de encontro entre um material psíquico recalcado e uma consciência: tensionamento que não se propicia na proposta da hipnose, a qual dificulta que se visibilizem os momentos de resistência a um tratamento.

3 LACAN, Função e Campo da Fala e da Linguagem.

4 LAPLANCHE, Problematiques VI.

${ }^{5}$ KOSELLECK, Futuro Passado: contribuição à semântica dos tempos históricos.

${ }^{6}$ BENVENISTE, O Aparelho Geral da Enunciação, 84.
} 
certa descrição - e portanto em maior ou menor medida produzida desde uma narrativa de ficção em um momento outro, a posteriori, que dispõe já de outro contexto de possibilidades de significação. Tais definições, ao aproximarem um fazer ficcional dos regimes constituintes de uma verdade ou uma realidade, permitem entendermos como o sentido se produz mais a partir de um acontecimento de reunião, em si, do que através das premissas que $o$ antecedem.

De fato, quando conceituamos as narrativas que se produzem em um contexto da psicanálise, é consenso de que há uma relação intrínseca entre um processo ficcional e as produções em um regime de verdade - conforme Lacan faz entender em suas colocações, às vezes de maneira explícita7. Isso é dizer que, desde um viés psicanalítico, as elaborações de um si-mesmo permitem ressignificações, retomadas de perspectiva sobre os acontecimentos de um passado e, ainda, reformulações de uma direção de futuro.

Neste ensejo, é possível assumir os liames entre um discurso e uma prática ao constatarem-se as conexões entre uma narrativa e as alternativas a um plano da realidade que a última evoca ou constitui - e esse entendimento talvez sirva para que valorizemos a potência da palavra enquanto meio de um ato. Quando Jacques Lacan ${ }^{8}$ procura uma definição para o último, ele se associa ao campo de uma linguística, situando-o como um significante que promove certo desvio à cadeia de significantes de que faz parte. Isso é dizer que, na leitura de Lacan, há algo que o ato traz de ruptura e de invenção - ao mesmo tempo que o mesmo mantém, enquanto um desvio, conexões com uma cadeia de expectativas ou prospectos anteriormente colocados.

\section{Ficcionalizar um si; formar por}

Ainda em diálogo com essas premissas de uma psicanálise, será necessário salientar a dimensão de uma palavra que, enquanto ato, pode funcionar como um elemento de desvio o qual pelo seu acontecimento oferece novas alternativas a uma verdade, a um conhecimento histórico, a uma realidade. John Langshaw Austin, em um texto intitulado How to do Things With Words ${ }^{9}$, lança a ideia do que ali se denomina uma elocução performativa. A expressão encontra ressonâncias no pensamento de teóricas da linguística, dos estudos de gênero e do feminismo, como Judith Butler, Shoshana Felman ${ }^{10}$, Eve Sedgwick ${ }^{11}$.

Butler especialmente traz uma ideia do performativo para demonstrar os meios pelos quais a recorrência de certas enunciações pode, de maneira iterativa e em nível micro, formar uma identidade. Fracionando este termo, performativo, e retomando sua origem no latim, temos os fragmentos per e formare, cuja ligação talvez nos indique uma ideia de "formar por". Quando Butler e outras autoras se detêm sobre esse conceito, algo de um movimento é sempre convocado para dizer de um processo, imprevisível tanto quanto irredutível, pelo qual a imagem de um eu se constitui. A ideia é importante para entendermos que o processo de identificação se produz muito a partir de um social - e também atua como um produtor dos regimes de reconhecimento deste, numa via em avesso. Por tais direções se elabora a formação de algo - que, ao se reiterar nas vias de um discurso, inventa, de forma sempre irredutível e não localizável, uma forma de gênero:

\footnotetext{
7 LACAN, O Seminário, Livro 4: As Relações de objeto, 258-259.

${ }^{8}$ LACAN, L'Acte Psychanalytique.

9 AUSTIN, How to do Things With Words.

${ }^{10}$ FELMAN, Le Scandale du Corps Parlant.

${ }^{11}$ SEDGWICK, Touching Feeling: Affect, Pedagogy, Performativity.
} 
o gênero não deve ser construído como uma identidade estável ou um locus de ação do qual decorrem vários atos; em vez disso, o gênero é uma identidade tenuemente constituída no tempo, instituído num espaço externo por meio de uma repetição estilizada de atos. O efeito do gênero se produz pela estilização do corpo e deve ser entendido, consequentemente, como a forma corriqueira pela qual os gestos, movimentos e estilos corporais de vários tipos constituem a ilusão de um eu permanentemente marcado pelo gênero ${ }^{12}$.

Desde Problemas de Gênero esta é uma noção que acompanha a trajetória da autora, sendo ao longo dos anos articulada com outras instâncias - como os regimes de normatividade que selecionam as vidas que são passíveis de luto em relação àquelas cuja perda não é pranteável ${ }^{13}$, bem como os termos e as possibilidades pelos quais tais formas identitárias assumidas como abjetas à normalidade encontrarão um reconhecimento ${ }^{14}$. Merece destaque aqui, principalmente, a forma como podemos entender, junto a Butler e uma noção de elocução performativa, os meios pelos quais o dizer de uma palavra define, discursiva e materialmente falando, os regimes de possibilidade onde se insere. Tal dizer é definido também por estes mesmos circuitos, em uma lógica que de alguma maneira aproxima dizer e fazer.

No caso específico de uma identidade de gênero, será importante dizer que há algo, no simples nomear-se, que inventa, constitui e situa já algo dessa identidade. Também para a psicanálise, as dimensões de uma nomeação são cruciais para que se possa entender uma visão de um si tanto quanto uma constituição psíquica.

Portanto falamos, através da sobreposição de algumas vias do pensamento, de uma relação entre palavra e ato. $\mathrm{O}$ que se pretende analisar mais além no presente texto, ainda por perspectivas diversas, são as relações entre estas duas instâncias, que em alguns momentos e de maneiras variadas se podem perceber pela ideia de feitiço.

\section{Feitiço}

Tendo sido feitas as colocações até aqui, espero ser evidente que o conceito de feitiço não se resume aos jargões hocus pocus ou abracadabra, vazios já de sentido pela sua repetição desimplicada (apesar de sua história remeter a tempos muito remotos, em que seus poderes tinham outro valor) ${ }^{15}$.

Quando tratamos aqui de um feitiço, falamos de uma enunciação que, ao ocupar certo lugar e certo tempo, influencia as dimensões de uma materialidade. Trazendo a definição geral para uma mais específica, será pertinente referir a força incomensurável que pode ter uma enunciação no momento singular em que esta se produz, salientando os desvios que se podem fazer a partir de seu acontecimento.

\footnotetext{
12 BUTLER, Problemas de Gênero, 200, grifos da autora.

${ }^{13}$ BUTLER, A Vida Psíquica do Poder; BUTLER, Frames of War.

14 BUTLER, Corpos em Aliança e a Política das Ruas; BUTLER, The Force of Nonviolence: An Ethico-Political Bind.

15 A expressão abracadabra, similar ao aramaico avra kehdabra (traduzível por "criarei enquanto falo"), tem registro de usos em rituais de cura desde um tempo anterior ao do século II a.C. Conta-se que sua escrita em formato triangular, cuja repetição em sobreposição subtraía uma letra da repetição anterior, curava doenças como a malária. Imagina-se também que hocus pocus seja uma contração originada do latim hoc est enum corpus meum (este é o meu corpo).
} 
Psicanalistas ou analisantes poderão se lembrar dos momentos de uma elaboração, na clínica, em que o dizer de uma simples frase faz emergir uma cadeia de outros elementos, que já estavam ali, mas que a partir de uma enunciação tomam o estatuto de existência e, perceptivelmente, passam a operar outras vias no contexto em que se produzem. A fim de não restringirmos os potenciais do que quer se dizer aqui a estes campos, podemos tomar exemplos como os da assinatura de uma demissão, da simples caracterização de um si nos momentos em que lhe são exigidas apresentações, ou do mostrar do resultado da votação de uma decisão democrática como situações que analogamente carregam esta característica de uma definição através de uma enunciação. De maneira similar ao que se diz em outros escritos deste texto sobre o ato, importará trazer para discussão sobre um feitiço estes que se colocam como atos ou pontos de virada, em que algo de uma direção se altera em maior ou menor medida - e cuja existência só se possibilita a partir de uma construção de um contexto (resta saber se intencional ou não).

Faço mais uma ressalva a fim de evidenciar que não se deve confundir um feitiço que se refere aqui com aquele da feitiçaria de um capitalismo ${ }^{16}$, cujos fins e as formas se associam menos às dimensões de um não-saber do acontecimento e mais aos encantamentos de um fetiche limitado. No último caso, estamos ainda habitando os domínios de uma magia; esta em específico se coloca, no entanto, a serviço de uma repetição superficial e procura sempre estabelecer associações já hegemonicamente constituídas.

Neste momento talvez valha lembrar as novas leituras que Lacan ${ }^{17}$ propõe quando apresenta um discurso do capitalismo. Na ocasião de um seminário sobre o avesso da psicanálise, ele trabalhará a especificidade deste circuito de agências discursivas para dizer de um gozo que se faz circunscrito às opções que oferece um consumismo. Ou seja, no caso de um discurso capitalista, a premissa é a de que o objeto que causa desejo, entendido alhures como instância incapturável, agora toma as formas de um produto, cuja possessão inclusive se mostra aparentemente vendável ${ }^{18}$.

Também é verdade que Lacan definirá, em seminário anterior sobre as relações de objeto $^{19}$, que o fetiche e o medo se colocam como tentativas de objetalizar a angústia. Na senda de uma discussão sobre o feitiço, parece fundamental indagar a relação direta entre o fetiche e uma ideia de limitação; isso porque, em contraponto à leitura desvalorizante que se pode fazer deste conceito a partir de psicanálises mais conservadoras, podemos pensar em uma leitura ao avesso - uma que entende que, justamente ao permitir denunciar certos automatismos, o fetiche carrega em si também certa potência de transgressão de um status quo e de constituição e afirmação de práticas desviantes, que pela sua agência guardam afinidades com uma lógica do feitiço.

É em direções afins que Bruno Latour ${ }^{20}$ faz colocações a respeito de um faitiche palavra que na língua francesa permite retomar as conexões históricas entre o feitiço, o fetiche (fétiche) e o fato (fait). Ali, o autor se dedica a problematizar uma lógica moderna que, inclusive de maneira crítica a certas visões de mundo africanas, procura diferenciar e separar um objeto sagrado de um objeto assumidamente fabricado - supondo possível separar, da mesma forma, um falar de um fazer:

a escolha cominatória permanece; escolha evocada pelos portugueses e recusada pelos negros: "Quem fala no oraculo é o humano que articula ou o objeto-encantado? A divindade e real ou artificial?" - "Os dois", respondem

\footnotetext{
${ }^{16}$ STENGERS; PIGNARRE, La Sorcellerie Capitaliste.

${ }^{17}$ LACAN, O Seminário, Livro 17: O Avesso da Psicanálise.

${ }^{18}$ Sobre o assunto, ver ROSA, Jacques Lacan e a Clínica do Consumo.

19 LACAN, O Seminário, Livro 4: As Relações de Objeto.

${ }^{20}$ LATOUR, Reflexões sobre o culto moderno dos deuses fe(i)tiches.
} 
os acusados, sem hesitar, incapazes que são de compreender a oposição. - "É preciso que vocês escolham", afirmam os conquistadores, sem menor hesitação. As duas raízes da palavra indicam bem a ambiguidade do objeto que fala, que é fabricado ou, para reunir em uma só expressão os dois sentidos, que faz falar. Sim, o fetiche é um fazer-falar ${ }^{21}$.

A colocação contribui para que pensemos a potência de um dizer mesmo na constituição material de um objeto de análise. Em verdade, quando Latour coloca a ideia de feitiço nestes termos, através da ideia de um fazer-falar, parecem propícias as afinidades com um performativo e com uma dimensão de verdade que é ficcional, conforme discutíamos outrora.

Ainda procurando ler por vias avessas os eixos conceituais do trabalho de Lacan, podemos pensar o fetiche menos pelas vias de uma repetição simplesmente automatizada e mais pela potência que se pode produzir desde os mecanismos de um sintoma: neste caso, uma repetição que se permite perceber e dizer é justamente o que denuncia formas de gozo prejudiciais ou prescindíveis que se encontram inconscientemente sustentadas em paradigmas arbitrários que dizem respeito a uma lei. Conforme Butler indica ${ }^{22}$, talvez algo falhe no contexto histórico-filosófico de Lacan, que está muito às voltas com uma lógica edípica de um nome do pai para poder operar uma volta no próprio conceito de lei e entender como esta se produz, de maneira arbitrária, junto às práticas repetitivas que reitera e legitima.

Procurando atingir a discussão desde um ponto de vista que indica as potencialidades do fetiche na sua relação com os acontecimentos de um feitiço, será importante relacionar o primeiro mais diretamente a práticas de uma identidade sexual, conforme Gayle Rubin faz em entrevista com Judith Butler ${ }^{23}$. Ali a autora assume a potencialidade do fetiche que se dedica a questionar posições e práticas naturalizadas, balançando de alguma forma alguns stablishments identitários.

É talvez por percursos praticamente concomitantes que Silvia Federicci ${ }^{24}$ faz ver o outro lado dessa moeda, enlaçando o desenvolvimento de uma organização capitalista aos fenômenos de caça à bruxaria e de remanejo dos lugares e papéis designados às mulheres na comunidade. De maneira crítica, a visão da autora amplia e dá outro enfoque às relações de poder que se estabelecem no caminhar dos últimos séculos, apresentando as limitações de uma análise materialista histórica e oferecendo contrapontos importantes às colocações de Michel Foucault sobre o biopoder, ao mesmo tempo em que pauta o gênero como um eixo fundamental de discussão ${ }^{25}$.

Contra feitiço, feitiço e meio. De fato, parece que, quando discutimos os termos de um feitiço, fica implícito certo funcionamento que se dá em operações intermitentes de ação e reação. Dizer isso talvez possibilite compreendermos as formas deste acontecimento como uma instância poderosa que, na mesma medida em que pode operar de maneira construtiva ou benigna, também pode instaurar uma periculosidade potencialmente danosa e avassaladora.

\footnotetext{
${ }^{21}$ LATOUR, Reflexões sobre o culto moderno dos deuses fe(i)tiches, 17, grifos do autor.

${ }^{22}$ BUTLER, Corpos que Importam.

23 BUTLER, Sexual Traffic.

${ }^{24}$ FEDERICCI, O Calibã e a Bruxa.

25 Tais questões se fazem perpicazmente articuladas com os dizeres de um feminismo e de um marxismo pelas autoras DIETRICH e SEVERO em A Emergência do Capitalismo e as Mulheres - Uma Crítica Feminista Marxista.
} 
Este segundo semblante de um feitiço encontra ressonâncias no trabalho de Marina Vanzolini $^{26}$ - que se dedica a pensar sobre o contato dos povos Aweti, da região do Alto Xingu, com as formas de um capitalismo e um estilo de vida branco ${ }^{27}$. Ali, a autora conceitualizará o feitiço como uma agência prejudicial, ilustrada na presença de pequenas flechas que se atam à pele de uma vítima, ou se lançam em sua direção, e assim provocam seu adoecimento. Nesse sentido ela dirá que

só se morre de feitiço no Alto Xingu. Fato comum em outras partes da Amazônia (e alhures), o adoecimento e a morte são entendidos ali como resultado da ação intencional de um sujeito, humano ou não humano. Quando alguém adoece, portanto, a pergunta pertinente é menos "o que o está matando?”, mas antes “quem o está matando?”. É para a identificação desse agente que se volta boa parte da atividade xamânica. [...] Ainda que certos animais também possam fazer feitiços ou causar o adoecimento de alguém capturando sua alma, doenças graves e adoecimentos são sempre provocados por um agente humano, geralmente alguém social e geograficamente próximo da vítima ${ }^{28}$.

O artigo, que decorre de um processo de pesquisa etnográfica em produção desde $2006^{29}$, conclui quando a autora salienta que nesta conjuntura "há uma forma particular das conversas sobre feitiçaria que me parece levar em conta o fato de que uma acusação é sempre provisória” ${ }^{30}$, no sentido de que as recapitulações dos fatos se coloca sempre pelas vias de uma tentativa, estando assim mais aberta a especulações e a reestruturações de uma verdade até então colocada.

A leitura, além de possibilitar a retomada de alguns caminhos já assumidos por este artigo, também é propícia para que estabeleçamos um paralelo entre tal forma menos definitiva de construção de verdade e o que Isabelle Stengers e Philippe Pignarre ${ }^{31}$ parecem apresentar ao elaborarem a respeito de uma feitiçaria capitalista. Em seu livro, a autora e o autor procuram as alternativas a uma sistemática que passam não propriamente por um confronto direto aos mecanismos do capitalismo, mas talvez por uma postura estratégica que intenta redirecionar os seus fluxos - por vezes se valendo dos exatos mesmos termos e hábitos de sua natureza. Ambos procuram argumentar que de fato, se esta forma de organização se desenvolve através de uma lógica sistemática, deverá haver algum ponto cego ou nó onde esta fracassa em efetivar seus propósitos anteriormente deliberados. É neste instante singular de acontecimento que Stengers e Pignarre dirão que, por uma via da pragmática, se podem conceber reações de desenfeitiçamento às pretensões condicionantes de uma feitiçaria capitalista.

\section{Magia}

Até o momento, este texto procurou reunir alguns vieses que, para os fins de um argumento, trabalham com as dimensões de um ainda não sabido. Seja na singularidade dos processos que afirma uma psicanálise, na imprevisibilidade de uma identificação, nos

\footnotetext{
${ }^{26}$ VANZOLINI, O Feitiço e a Feitiçaria Capitalista.

${ }_{27}$ Assumo este termo, que a autora aponta como a tradução nativa mais comum para designar quem não é indío.

${ }^{28}$ VANZOLINI, O Feitiço e a Feitiçaria Capitalista, 328-329.

29 VANZOLINI, A Flecha do Ciúme: O parentesco e seu avesso segundo os Aweti do Alto Xingu.

30 VANZOLINI, O Feitiço e a Feitiçaria Capitalista, 335.

${ }^{31}$ STENGERS; PIGNARRE, La Sorcellerie Capitaliste.
} 
desvios propiciados do dizer de uma palavra, na impossibilidade de situar as decorrências do uso de um fetiche ou na provisoriedade que permite a lógica de um feitiço, nos casos apresentados aqui parece haver um entendimento de que existe uma réstia que resiste, sempre, aos modos de uma significação.

Isso porque qualquer sentido está sempre sujeito às movimentações de seu acontecimento $^{32}$. Tal noção parece conflituosa com as prescrições paradigmáticas dos dizeres de uma ciência em específico - e de fato, conforme Isabelle Stengers 33 inspira a pensar, o desafio talvez seja justamente o de oferecer contrapontos a estes paradigmas sem propor outros em seu lugar. É pela premência de tal proposta que parece pertinente retomar, aqui, os dizeres relacionados à magia no contemporâneo. Em um diálogo forte com o que entendemos por ciência e política, e em consonância com o que coloca Stengers, a ativista Miriam Simos Starhawk salienta as dimensões mágica e espiritual destes campos, trazendo para a baila uma discussão muito relacionada aos modos da ciência e de um capitalismo deste tempo. Em dado momentos de sua elaboração, Starhawk coloca:

Para aqueles de nós que acreditam que a ciência é real e importante e que precisamos prestar atenção a ela em tempos de mudança climática, também é importante entender que o modo como compreendemos a ciência hoje é apenas uma parte do que o conhecimento humano poderia potencialmente englobar se nos permitíssemos retornar, resgatar e reativar alguns desses antigos conhecimentos e compreensões ${ }^{34}$.

Quais são os limites de análise daquele pensamento que, ancorado numa suposição de ciência objetiva e concreta, supõe possível desvelar todos os mistérios da existência antes de seus acontecimentos?

Para os fins deste texto, interessa entender a magia como um campo que, por guardar relações como uma dimensão da ficção - e por conseguinte de algo cuja essência supõe algo de incapturável -, faz mão de um feitiço entendendo-o como um evento, situado nas condições energético-espaço-temporais em que se dá - e é, por esta razão mesma, imprevisível na mesma medida em que é singular.

De fato aqui o ficcional, pelo seu acontecimento através do feitiço, permite uma conjuração de tempos, mas também uma de corpos, de subjetividades, de elementos, pelas vias da construção, pelo singular, de algo em comum. Tal parece ser a direção que Tobie Nathan e Isabelle Stengers ${ }^{35}$ assumem, por exemplo, quando entendem a prática de uma escuta como algo sempre situado - e que portanto joga com as histórias que habitam o espírito do tempo e do espaço onde acontece ${ }^{36}$.

Espera-se que o argumento deste texto sirva para propor que há sempre algo do inexplicável, simultâneo e incapturável nas várias maneiras de pensar e agir. Dizer isso é considerar as decorrências de uma agência ou de um pensamento em um plano que extrapola as possibilidades humanas de entender, de alguma maneira, uma sistemática maior - a qual, no entanto, não deixa de operar por algum meio nas restrições destas possibilidades. Talvez pelos agenciamentos que se produzam nesta leitura possamos resgatar ou reativar a noção de que o humano e o não-humano estão exatamente no mesmo

\footnotetext{
${ }^{32}$ Neste texto, o conceito de acontecimento procura referir uma corrente filosófica atenta aos deslindes da relação entre percepção e sentido - cujas ressonâncias se fazem, por exemplo, em Lógica do Sentido, de Gilles Deleuze.

33 STENGERS, A Proposição Cosmopolítica.

34 STARHAWK, Magia, visão e ação, 58.

35 NATHAN; STENGERS, Médecins et Sorciers.

${ }^{36}$ Outro texto que faz importantes contribuições a uma prática de escuta que considera a dimensão de acontecimento do feitiço é o da psicanalista Victoria Larrosa, intitulado Curandería: Escucha Clínica, Perfomática y Gualichera.
} 
plano. Podemos por estes caminhos imaginar, junto às colocações de Donna Haraway ${ }^{37}$, Bruno Latour ${ }^{38}$ e Marisol de La Cadena ${ }^{39}$, , as conexões que atravessam tal linha imaginária, mostrando a arbitrariedade com que desenvolvemos essa diferença.

De fato, merecerá considerações esta expressão, reativar, que Stengers nos apresenta de maneira muito inspirada no neopaganismo de Starhawk - cujas práticas e implicações encontram-se elaboradas no trabalho de Salomonsen ${ }^{40}$. Stengers faz o termo operar enquanto reflete sobre uma "erradicação cultural e social - precursora do que foi cometido em nome da civilização e da razão" ${ }^{4}$. Em suas conexões com um processo narrativo e de produção memória, então reativar (traduzido do inglês reclaim) trata não apenas de uma retomada de algo que não foi tomado em um momento anterior - mas também de algo que se pode produzir em um momento presente. Em outro trabalho, Stengers ${ }^{42}$ associará o ato de reativar a uma pragmática, dizendo por linhas afins que, por esta ideia, não se trata de pegar de volta o que possa ter sido confiscado, mas pensar nas maneiras como podemos habitar novamente as instâncias ao nosso redor que se encontram devastadas ${ }^{43}$ : tarefa árdua e necessária, cujas pistas podemos encontrar talvez em trabalhos inspiradores como os de Anna Tsing44 e Starhawk45.De fato, o que Starhawk faz, ao falar sobre um contrafeitiço ${ }^{46}$, é indicar uma reinvenção que acontece pelas vias não de uma oposição, mas da construção narrativa que procura alternativas ao que está já colocado - pela tarefa de se perguntar: e se...?. E aqui novamente a dimensão de um ficcional merece ser retomada para que reflitamos - em um campo analítico, mágico ou performativo - sobre a potência que uma enunciação pode ter sobre os regimes de produção do possível.

Restam os dizeres do feitiço:

Como aceitar a regressão ou a conversão a crenças sobrenaturais? A questão aqui, contudo, não é nos perguntarmos se devemos "aceitar" a Deusa que as bruxas contemporâneas invocam em seus rituais. Se disséssemos: "Mas a sua Deusa é apenas uma ficção", sem dúvida elas sorririam e perguntariam se somos daquelas pessoas que acreditam que a ficção não tem poder ${ }^{47}$.

\section{Referências}

AUSTIN, J. L. How do Do Things With Words. London, Oxford University Press, 1962.

BUTLER, J. Sexual Traffic. In: Differences: A Journal of Feminist Cultural Studies, v.6, n. 2-3, p. 64, 1994. Disponível em:

\footnotetext{
37 HARAWAY. Manifesto Ciborgue.

${ }^{8}$ LATOUR. Jamais Fomos Modernos.

39 CADENA. Human but not only.

40 SALOMONSEN, Enchanted Feminism: Ritual, Gender and Divinity among the Reclaiming Witches of San

Francisco.

${ }^{41}$ STENGERS. Reativar o Animismo, p. 9.

${ }^{22}$ STENGERS. Experimenting with Refrains: Subjectivity and the Challenge of Escaping Modern Dualism

43 Tanto em Experimenting with Refrains quanto em Reativar o Animismo a autora associa os agenciamentos discursivos a uma prática - e pensa desde aí sua importância fundamental para uma ecologia.

44 TSING, A. The Mushroom at the End of the World: On the Possibility of Life in Capitalist Ruins.

45 STARHAWK. Webs of Power: Notes from the Global Uprising.

${ }^{46}$ STARHAWK. Webs of Power: Notes from the Global Uprising, p. 155-158.

47 STENGERS, A Proposição Cosmopolítica, p. 12.
} 
https://go.gale.com/ps/anonymous?id=GALE\%7CA17250594\&sid=googleScholar\&v=2.1\&it=r

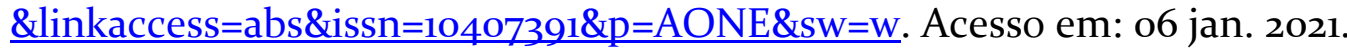

BUTLER, J. Problemas de gênero: feminismo e subversão da identidade. Trad. Renato Aguiar. Rio de Janeiro: Civilização Brasileira, 2003 (original publicado em 1990).

BUTLER, J. Quadros de Guerra. Quando a vida é passível de luto? Trad. Sérgio Lamarão e Arnaldo Marques da Cunha Rio de Janeiro: Civilização Brasileira, 2015 (original publicado em 2009).

BUTLER, J. A Vida Psíquica do Poder: teorias da sujeição. Trad. Rogério Bettoni. Belo Horizonte: Editora Autêntica, 2018 (original publicado em 1997).

BUTLER, J. Corpos em Aliança e a Política das Ruas. Trad. Fernanda Siqueira Miguens. Rio de Janeiro: Civilização Brasileira, 2018 (original publicado em 2015).

BUTLER, J. Corpos que Importam: Os limites discursivos do 'sexo'. Trad. Veronica Daminelli e Daniel Yago Françoli. São Paulo: n-1 edições; Crocodilo Edições, 2019 (original publicado em 1993).

BUTLER, J. The Force of Nonviolence: An Ethico-Political Bind. London: Verso, 2020.

CADENA, M. Human but not only. Hau: Journal of Ethnographic Theory, v. 4, n. 2, p. 253259, 2014. Disponível em: https://www.journals.uchicago.edu/doi/pdfplus/10.14318/hau4.2.013. Acesso em: o6 jan. 2021.

DELEUZE, G. Lógica do Sentido. São Paulo: Perspectiva, 1974.

DIETRICH, P.; SEVERO, C. A Emergência do Capitalismo e as Mulheres - Uma Crítica Feminista Marxista. Temáticas, Campinas, v. 26, n. 52, p. 315-326, 2018. Disponível em: https://doi.org/10.20396/temáticas.v26i52.11713. Acesso em: o6 jan. 2021.

FEDERICCI, S. O Calibã e a Bruxa: Mulheres, Corpo e Acumulação Primitiva. Trad. Coletivo Sycorax. São Paulo: Editora Elefante, 2017 (original publicado em 2004).

FELMAN, S. Le Scandale du Corps Parlant: Don Juan avec Austin, ou, la seduction en deux langues. Paris: Editions du Seuil, 1980.

FREUD, S. O Método Psicanalítico de Sigmund Freud. In: Edição Standard Brasileira das Obras Psicológicas Completas de Sigmund Freud, Vol. VII. Rio de Janeiro: Imago, 1980 (original publicado em 1904).

FREUD, S. Recordar, repetir e elaborar (Novas recomendações sobre a técnica da Psicanálise II). In: Freud, S. Vol. XII. Rio de Janeiro: Imago, 198o (original publicado em 1914).

FREUD, S. A Dinâmica da Transferência. In: Freud, S. Edição Standard Brasileira das Obras Psicológicas Completas de Sigmund Freud, Vol. XII. Rio de Janeiro: Imago, 198o (original publicado em 1912).

HARAWAY, D. A Cyborg Manifesto. Mineapolis: University of Minnesota Press, 2016.

KOSELlECK, R. Futuro Passado: contribuição à semântica dos tempos históricos. Trad. Wilma Patrícia Maas e Carlos Almeida Pereira. Rio de Janeiro: Contraponto, 2006 (original publicado em 1979).

LACAN, J. O Seminário, Livro 17: O Avesso da Psicanálise. Trad. Ari Roitman. Rio de Janeiro: Jorge Zahar Editor, 1992 (original publicado em 1969-70).

LACAN, J. O Seminário, Livro 4: As Relações de Objeto. Trad. Dulce Duque Estrada. Rio de Janeiro: Jorge Zahar Editor, 1995 (original publicado em 1956-57). 
LACAN, J. Função e Campo da Fala e da Linguagem. In: Escritos. Trad. Vera Ribeiro. Rio de Janeiro: Zahar, 1998 (original publicado em 1953).

LACAN, J. L'Acte Psychanalytique. Versão Digital Staferla, 2018 (original publicado em 196768).

LAPLANCHE, J. Problematiques VI: l'après-coup. Paris: PUF, 1990-91.

LARROSA, V. Curandería: Escucha Clínica, Perfomática y Gualichera. Buenos Aires: Hekht libros, 2017.

LATOUR, B. Jamais Fomos Modernos. São Paulo: Editora 34, 1994.

LATOUR, B. Reflexão sobre o culto moderno dos deuses fe(i)tiches. Trad. Sandra Moreira. EDUSC, 2002.

NATHAN, T.; STENGERS, I. Médecins et sorciers. Paris: Éditions La Découverte, 2012.

ROSA, M. Jacques Lacan e a Clínica do Consumo. Psicologia. Clinica, v.22, n.1, p.157-171, 2010. Disponível em: https://doi.org/10.1590/So103-56652010000100010. Acesso em: o6 jan. 2021.

SALOMONSEN, J. Enchanted Feminism: Ritual, Gender and Divinity among the Reclaiming Witches of San Francisco. New York: Routledge, 2002.

SEDGWICK, E. K. Touching Feeling: Affect, Pedagogy, Performativity. Durham: Duke University Press Books, 2003.

STARHAWK. Webs of Power: Notes from the Global Uprising. Gabriola: New Society Publishers, 2002

STARHAWK, M. S. Magia, visão e ação. Revista Do Instituto De Estudos Brasileiros, n. 69, p. 52-65, 2018. Disponível em: https://doi.org/10.11606/issn.2316-901X.voi6gp52-65. Acesso em: o6 jan. 2021.

STENGERS, I.; PIGNARRE, P. La Sorcellerie Capitaliste. Paris: Editions La Découverte, 2005.

STENGERS, I. Experimenting with Refrains: Subjectivity and the Challenge of Escaping Modern Dualism. Subjectivity, v 22, n. 1, p. 38-59, 2008. Disponível em: https://link.springer.com/article/10.1057/sub.2008.6. Acesso em: 06 jan. 2021.

STENGERS, I. Reativar o animismo. In: Caderno de Leituras, n. 62. Trad. Jamille Pinheiro Dias. Belo Horizonte: Editora Chão da Feira, 2017.

STENGERS, I. A Proposição Cosmopolítica. Revista do Instituto de Estudos Brasileiros, Brasil, n. 69, p. 442-464, 2018. Disponível em: https://doi.org/10.11606/issn.2316-901X.voi69p442464. Acesso em: 06 jan. 2020.

TSING, Anna. The Mushroom at the End of the World: On the Possibility of Life in Capitalist Ruins. New Jersey: Princeton University Press, 2015.

VANZOLINI, M. A Flecha do Ciúme: Parentesco e seu avesso segundo os Aweti do Alto Xingu. Tese de doutorado. Rio de Janeiro: Museu Nacional, 2010. Disponível em: https://acervo.socioambiental.org/sites/default/files/documents/AEToooo1.pdf. Acesso em: o6 jan. 2021.

VANZOLINI, M. O Feitiço e a Feitiçaria Capitalista. Revista do Instituto de Estudos Brasileiros, Brasil, n. 69, p. 324-337, 2018. Disponível em: https://doi.org/10.11606/issn.2316901X.voi6gp324-337. Acesso em: o6 jan. 2021. 